\title{
The impact of financial variables on firms' real decisions: evidence from Spanish firm-level data
}

\author{
IGNACIO HERNANDO* \\ Banco de España
}

\author{
Carmen Martínez-Carrascal ${ }^{\dagger}$ \\ Banco de España
}

June 2005

\begin{abstract}
This paper analyses the impact of alternative measures of firms' financial health on their investment and employment decisions. Using disaggregated data, we find that corporate financial position affects business activity and this impact is more intense when financial pressure exceeds a certain threshold. Composite indicators that summarize this non-linear impact suggest that specially in episodes where the financial pressure on a significant number of firms reaches levels at which it has a pronounced influence on real activity, indicators based on aggregate data may not reliably reflect the system's financial soundness since they do not adequately reflect the vulnerability of the most fragile companies.
\end{abstract}

JEL Codes: C33, E22, G32, J23.

Key words: financial conditions; fixed investment; employment.

Acknowledgements: This paper represents a follow-up of previous joint work with Andrew Benito, to whom we are very grateful. We also thank Juan Ayuso, Roberto Blanco, Jorge Martínez-Pagés, Fernando Restoy, Javier Vallés, and participants in the BIS Autumn 2003 Central Bank Economist's Meeting, and in the seminar held at the Banco de España for helpful comments and the Central Balance Sheet Data Office of the Banco de España for providing the data. The views expressed are those of the authors and should not be attributed to the Banco de España.

\footnotetext{
${ }^{*}$ Banco de España, Servicio de Estudios, Alcalá 50, 28014 Madrid, Spain. Tel: +34 91338 5186. E-mail: hernando@bde.es

†Banco de España, Servicio de Estudios, Alcalá 50, 28014 Madrid, Spain. Tel: +34 91338 5723. E-mail: carmen.martinez@bde.es
} 


\section{Introduction}

The financial position of the corporate sector may influence the performance of the real economy and the stability of the financial system through its contribution to aggregate demand and its links to the banking system and capital markets. Thus, for instance, excessive indebtedness may restrict the ability of companies to access additional external funds and, as a consequence, it may adversely affect their expansionary capacity. In fact, adjustment by companies to changes in the financial pressure they face (for instance, as a result of a monetary policy shift) can potentially involve a wide range of activities, with the most prominent relating to their investment decisions, human resource policies and financial policies (see Benito and Young, 2002 or Benito and Hernando, 2002). Therefore, the analysis of the financial health of the corporate sector is an important ingredient for an adequate assessment of the macroeconomic outlook.

From the standpoint of identifying the risks to macroeconomic and financial stability, it should be borne in mind that basing the assessment of the financial position of companies on an analysis of aggregate sectoral indices may, while being informative, occasionally cover up vulnerabilities that only a study at a greater level of detail can reveal. Therefore, this paper investigates the impact of financial variables on real activity, placing the emphasis on the analysis of disaggregated data. In particular, making use of microeconometric methods (panel techniques) and itemised data from a sample of the non-financial firms reporting to the Banco de España Central Balance Sheet Data Office Annual Database for the period 19852001, we analyse the sensitivity of fixed investment and employment to a relatively broad set of indicators that are usually considered to characterise the financial position of firms. Among these, we include variables providing information on corporate profitability, financial burden and indebtedness.

In our view, the main value added of the paper is twofold. First, we evaluate whether the impact of the financial position on business decisions is non-linear. In particular, our conjecture is that this relationship becomes relatively more intense when financial pressure exceeds a certain threshold. Furthermore, we analyse whether the relevant threshold differs depending on the real decision considered. Second, in the light of the estimated impacts of 
the different financial variables on firms' real decisions, we construct a composite indicator of financial pressure as a weighted average of different financial variables. Again, we investigate to what extent the weights attached to the different financial proxies differ for employment and for fixed investment.

The remainder of the paper is organised as follows. Section 2 provides a preliminary look at the descriptive information of the cross-sectional distribution of financial variables offering an overall assessment of financial pressure experienced by the Spanish corporate sector over the period 1985 to 2001. Section 3 describes the baseline specifications for fixed investment and employment, summarises the estimation methods and presents the basic estimation results. Section 4 analyses whether the impact of the financial position on corporate decisions becomes relatively more intense when financial tightness exceeds a certain threshold, whilst Section 5 constructs composite indicators of financial pressure, in the light of the estimated impacts of the different financial variables on firms' real decisions. Finally, Section 6 concludes.

\section{The financial position of the Spanish corporate sector: a preliminary look at firm-level data}

With perfect capital markets, the value of a firm is not determined by its financial structure and, consequently, the real activity of the firm is independent of its financing choice (Modigliani and Miller, 1958). However, financial markets are not perfect. The existence of capital market frictions (asymmetric information problems, agency conflicts between shareholders and managers, distortionary taxation) implies the break-up of the separation between investment and financing decisions. Hence, the financial performance and financing decisions of firms as well as their responses to financial pressure are important to both a country's macroeconomic conditions and the stability of its financial system. Furthermore, when assessing the risks to macroeconomic and financial stability, it should be borne in mind that the fragility of certain firms will not necessarily be offset by the soundness of others. Accordingly, the use of aggregate indicators to assess the financial position of the corporate sector and 
its impact on real activity may be inadequate. Indeed, the behaviour of the companies most exposed financially is, for these purposes, as relevant (if not more so) as the average behaviour of the sector. Against this background, the purpose of this section is twofold. First, we attempt to provide an overall picture of the financial position of Spanish non-financial companies and its evolution over the period considered. Second, we try to assess to what extent the real behaviour -more precisely, the demand for factors of production- of the more financially vulnerable firms differs from that of firms with an average financial position.

The firm-level data in this study were obtained from the Central Balance Sheet Data Office of the Bank of Spain. It included data from 7,547 firms over the 1985-2001 period, with a total number of 70,625 firm-years observations (see Data Appendix). This section presents, in primarily graphical form, an evaluation of the financial situation of the Spanish corporate sector. This analysis first illustrates variation in the cross-sectional distributions of financial variables and how these distributions have changed over time ${ }^{1}$. Then, a comparison is made of the behaviour of investment and labour demand for various sets of firms defined in terms of their financial position, using alternative indicators to proxy the degree of financial pressure on the companies.

First, we consider a narrow definition of the debt-service burden that is defined as the ratio of interest payments on debt to the company's gross revenue (interest debt burden), whose variation reflects a combination of changes in interest rates, company profitability and indebtedness. The cross-sectional distribution of this variable and how it varies over time is shown in Figure 1.1. Different percentiles (ie. the 25th, 50th, 75th, and 90th) in the crosssectional distribution for each year are displayed. The experience of the median company (the 50th percentile) is indicative of the typical Spanish company in each year, whilst the higher percentiles indicate the experience of those companies facing more intense financial pressure. The variable peaked in 1993 from which point it has declined steadily. An important finding from Figure 1.1 is that as interest rates have fallen from the mid-1990s, the implied reduction in financial pressure has been felt throughout the cross-sectional distribution of firms in Spain and, indeed, is strongest for the more financially vulnerable. This is a positive development

\footnotetext{
${ }^{1}$ See the Data Appendix for more precise definitions of the variables used in the paper and for median values of these variables over different subsample periods.
} 
for the financial stability associated with the corporate sector in Spain. It also contrasts with the experience during the recession, at its deepest in 1993, when the financial pressure on the most vulnerable companies increased relative to the more typical companies suggesting that aggregate data on debt burdens at the time understated the vulnerability of the most fragile companies and hence of the system as a whole. A very similar pattern emerges when considering a broader measure of the debt-service burden as a proportion of gross revenue that includes not only interest payments but also the stock of short-term debt (see Figure $1.2)$.

The cross-sectional distribution of corporate indebtedness, defined as the ratio of total outstanding debt to total assets, is illustrated in Figure 1.3. Similarly, Figure 1.4 depicts the cross-sectional distribution of net indebtedness. Both figures show a remarkable stability in the cross-sectional distribution of indebtedness of firms. The stability of the cross-sectional distribution of indebtedness among Spanish firms also contrasts with findings for UK quoted firms where a marked increase in dispersion in recent years has been found (Benito and Vlieghe, 2000).

Figures 1.5 and 1.6 illustrate two measures of profitability: gross revenue and cash-flow, in both cases divided by total assets. Two key observations arise from these figures. First, profitability is clearly procyclical as we would expect. Second, the experience of the median firm understates variation at the upper tail of the cross-sectional distribution, and in the case of the cash-flow measure also at the lower tail. For financial stability issues it is the lower tail that is more relevant and here (i.e. at the 10th percentile) cash-flow over total assets fell from $1.7 \%$ in 1988 to $-7.5 \%$ in 1993 .

This descriptive analysis has shown that there is substantial cross-sectional variation in the distribution of Spanish firms for each of the variables examined. To the extent that the real behaviour differs across companies facing different degrees of financial pressure, the assessment of the financial position of the corporate sector should ideally adopt a disaggregated perspective. To emphasise the relevance of this issue, in what follows we illustrate how investment in physical capital and labour demand differ across companies with different financial positions. For this purpose, Figure 2 compares the average level of both real variables 
in different corporate groupings defined on the basis of their financial position, proxied by alternative indicators. Each panel of the figure presents the average value of a real variable (the investment rate or the growth rate of employment) for the firms belonging to three different deciles of the distribution defined in terms of a financial indicator (the interest debt burden, the total debt burden, the debt ratio or gross revenue over total assets). The median decile (that including the firms between percentiles 45 and 55) can be regarded as representative of the behaviour of a firm in an average financial position. Analogously, the top (bottom) decile includes the $10 \%$ of firms with the highest (lowest) value of the corresponding financial indicator.

First, Figures 2.1 and 2.2 compare the behaviour of firms facing different degrees of financial pressure, this being proxied by means of a measure of the relative burden of debt (or, in other words, of the firms' capacity to meet interest and short-term debt payments), i.e. our total debt burden $(t d b)$ variable. This variable, being the net result of changes in interest rates, in corporate profitability and in corporate debt, is a relevant indicator of the financial pressure firms may be facing. In Figures 2.1 and 2.2, no marked differences in demand for factors of production are observed between the firms with lowest financial pressure and those with average financial pressure. However, firms with a higher financial burden in relation to their capacity to generate funds from operations have substantially lower investment and employment growth rates. Moreover, in the case of employment, this difference seems more marked in recessionary phases ${ }^{2}$.

Interestingly, the pattern of results changes when the level of indebtedness is used as the indicator of financial tightness. Thus, in Figure 2.3, the observed relationship between the investment rate and the debt ratio is not monotonic. Similarly, no significant differences in employment growth are observed among the three deciles considered (Figure 2.4). This absence of a clear relationship between the debt level and the level of activity at the company level may be interpreted as the consequence of two opposite effects. On the one hand, firms with high indebtedness may experience difficulties in gaining access to additional credit to finance new investment projects, but, on the other hand, those companies with higher lev-

\footnotetext{
${ }^{2}$ Similar conclusions can be drawn when the comparison is established in terms of our interest debt burden variable $(i d b)$.
} 
els of investment and employment growth are those companies that have been successful in attracting external funds to take advantage of their growth opportunities

Finally, Figures 2.5 and 2.6 show a clear link between the level of profitability and the demand for factors of production. Firms with higher levels of gross revenues over total assets have substantially higher investment and employment growth rates.

Overall, the evidence in this section suggests: first, that there is a substantial dispersion in the distribution of Spanish firms in terms of several indicators of the degree of financial tightness they face. Second, that financial position affects business activity; and, third, that this impact is not linear and becomes relatively more intense when financial pressure exceeds a certain threshold.

\section{The impact of financial variables on firms' real decisions}

The estimation analysis in this section considers the responsiveness of fixed investment and employment to changes in the financial conditions facing a company, proxied by a set of financial variables. These variables include indicators providing information on corporate profitability, indebtedness and the relative burden of debt and try to capture the degree of financial pressure firms may be facing. More precisely, the financial variables considered are: the total debt burden, $t d b$, net indebtedness, $((B-m) / A)$, and gross revenue over total assets, $(G R / A)^{3}$. Finally, we also consider an indicator of the probability of default that has been constructed using the estimated coefficients of a Probit model for the probability of default estimated by Benito et al. (2004) for a similar sample of Spanish non-financial firms.

\subsection{Baseline specifications}

The model estimated for fixed investment is an error-correction model which specifies a target level of the capital stock and allows for a flexible specification of the short-run investment dynamics, in which we add different financial indicators as potential explanatory variables. More structural models, such as Q models, would be more appropriate from a theoretical

\footnotetext{
${ }^{3}$ The results of the analysis below do not qualitatively change when we use the interest debt burden, $i d b$, total debt, $(B / A)$, and cash-flow over total assets, $(C F / A)$, as indicators of corporate profitability, indebtedness and debt burden, respectively.
} 
point of view, because they control for expectational influences on the investment decision and it can therefore be argued that financial variables should not enter this specification as proxies for future investment opportunities (see, for example, Fazzari et al., 1988). However, this type of models may be significantly affected by measurement error and have often failed to produce significant and correctly signed key parameters. For this reason, we estimate an error correction model of investment, which is standard in the investment literature. ${ }^{4}$ As is emphasised in Bond et al. (1999), this model, when estimated, usually displays reasonable long-run and short-run properties.

Starting from a general expression for the desired capital stock, assuming an autoregressivedistributed lag specification for the short-run dynamics, subsuming the depreciation rate into the unobserved firm-specific effects and assuming that variation in the user cost of capital can be controlled for by including both time-specific and firm-specific effects, the following specification for the investment rate can be obtained ${ }^{5}$ :

$$
\left(\frac{I}{K}\right)_{i t}=\alpha_{i}+\beta_{1}\left(\frac{I}{K}\right)_{i t-1}+\beta_{2} \Delta y_{i t}+\beta_{3} \Delta y_{i t-1}+\beta_{4}(k-y)_{i t-2}+X_{i t}^{\prime} \gamma+\theta_{t}+\varepsilon_{i t}
$$

where $i$ indexes companies $i=1 \ldots N$ and $t$ indexes years, $t=1 \ldots T . \Delta$ denotes a first difference, $I / K$ is the investment rate, $y$ is the $\log$ of real sales, $k$ is the log of real fixed capital stock, $\alpha_{i}$ are company-specific fixed effects, and $X$ represents a vector of financial variables. $\theta_{t}$ are time effects that control for macroeconomic influences on fixed investment common across companies and $\varepsilon_{i t}$ is a serially-uncorrelated, but possibly heteroskedastic error term. The coefficients $\beta_{2}$ and $\beta_{3}$ indicate the short-run responsiveness of fixed investment to sales growth, whilst the coefficient $\beta_{4}$ indicates the speed of adjustment of the capital stock towards its desired level.

The labour demand equation is derived from a quadratic adjustment cost model. For this reason, we include lagged employment as a regressor. We then add financial factors, as in Nickell and Nicolitsas (1999). Therefore, the demand equation takes the following form:

\footnotetext{
${ }^{4}$ In any case, a Q model is not possible here, since most of the Spanish firms are not quoted so that the usual $\mathrm{Q}$ variable cannot be constructed.

${ }^{5}$ See Bond et al. (1999) or Bond et al. (2003) for details on the derivation of the investment model.
} 


$$
n_{i t}=\phi_{i}+\lambda_{1} n_{i t-1}+\lambda_{2} k_{i t}+\lambda_{3} w_{i t-1}+\lambda_{4} \Delta w_{i t}+\lambda_{5} \xi_{i t}+X_{i}^{\prime} \eta+\Psi_{t}+\mu_{i t}
$$

where $i$ indexes companies $i=1,2 . . N$ and $t$ indexes year $\mathrm{t}=1,2 . . T . n$ is (log) average company employment during the year, $w$ is the $(\log )$ average real wage at the company, $k$ denotes $(\log )$ real fixed capital stock. $\xi$ is a demand shock proxy which consists of the growth in log real sales and $\Psi_{t}$ represents a set of common time effects (year dummies) which will control for aggregate effects including aggregate demand. ${ }^{6} \mu_{i t}$ is a serially uncorrelated but possibly heteroskedastic error term.

Two elements in equation (2) depart from what is a standard specification for labour demand. First, financial factors, represented by the regressors $X_{i}$, are included. Despite the extensive literature considering a potential role for financial conditions in shaping fixed investment (see Hubbard, 1998), there are few studies which allow for such a role in the context of labour demand models. ${ }^{7}$ Second, the model includes a demand shock variable, $\xi_{i t}$, following Bentolila and Saint-Paul (1992). Nevertheless, as in the case of fixed investment, a note of caution should be introduced since this reduced-form model of labour demand does not control for expectational influences and therefore, it might be argued that financial variables are to some extent capturing future demand.

\subsection{Estimation method}

The estimation method consists of the GMM-System estimator proposed by Arellano and Bover (1995) and examined in detail by Blundell and Bond (1998). These models control for fixed effects, with the estimator being an extension of the GMM estimator of Arellano and Bond (1991), which estimates equations in levels as well as in first-differences.

Appart from the bias that would arise if fixed effects were not controlled for, it is also necessary to note that most current firm-specific variables are endogenous. In order to avoid the bias associated with this endogeneity problem, we use a GMM estimator taking lags of

\footnotetext{
${ }^{6}$ The demand shock variable is not considered in the analysis of Nickell and Nicolitsas (1999), but it was included in a similar specification by Bentolila and Saint-Paul (1992).

${ }^{7}$ Some exceptions are Nickell and Wadhwani (1991), Nickell and Nicolitsas (1999) and Ogawa (2003).
} 
the dependent and explanatory variables as instruments.

The use of a GMM-System estimator is justified because in autoregressive models with high persistence in the data such that the lagged levels of a variable are not highly correlated with the first difference, the first-differenced estimator may be subject to finite sample biases associated with weak instruments (see Blundell and Bond, 1998). Blundell and Bond (1998) show that in these circumstances also including the levels equations in the system estimator offers significant gains, countering the bias. Blundell and Bond (1998) also show that in autoregresive-distributed lag models, first-differences of the variables can be used as instruments in the levels equations provided that they are mean stationary. The high levels of serial correlation displayed by several variables included in the models and the fact that most of them can be regarded as mean stationary favour the use of a GMM-System estimator.

The estimation method requires the absence of second order serial correlation in the first differenced residuals for which the test of Arellano and Bond (1991) is presented (labelled $M_{2}$ ). If the underlying model's residuals are indeed white noise then first-order serial correlation should be expected in the first-differenced residuals for which we also present the test of Arellano and Bond (1991), labelled $M_{1}$. We also report the results of the Sargan test for instrument validity in the GMM-System equations and the Difference-Sargan statistic, which test the validity of the additional moment conditions associated with the levels equations.

\subsection{Basic results}

Table 1 reports estimation results for fixed investment. Column 1 reports the results of the basic specification without financial variables. We generally find insignificant levels of persistence in company-level investment, a result quite consistent with results reported by Bond et al. (2003). The error-correction term $(k-y)_{i t-2}$ is correctly signed and statistically significant with coefficient (robust standard error) of -0.175 (0.022) implying a reasonable speed of adjustment, comparable to that obtained in similar studies. The sales growth terms are positive and significant and their magnitude is in the upper range of the values usually obtained in the literature. We find the expected first-order serial correlation in our firstdifferenced residuals while there is no evidence of second order serial correlation, the key 
requirement for validity of our instrumentation stategy and the Sargan test statistics are insignificant at conventional levels. ${ }^{8}$

We then consider adding the financial variables to the basic specification. Columns 2 to 8 of Table 2 report the estimates of the basic specification augmented with one financial variable at a time. First, column 2 adds net indebtedness, $(B-m) / A^{9}$ to the standard specification. The expected negative coefficient is obtained suggesting that a high level of debt can lead to balance sheet adjustment in the form of companies deferring or foregoing investment projects (see also Vermeulen, 2002 for an industry-level study). Second, in column 3 a significantly negative and well-determined effect is found for the total debt-burden, $t d b$. This indicates that the financial pressure of debt servicing plays an important role in influencing investment levels of firms. Third, the estimate in columns 4 includes an indicator of corporate profitability, $(G R / A)$. Its coefficient is significantly positive, which is consistent with studies of investment for other countries. As has been extensively discussed in the literature on investment and financial constraints, the cash-flow term might be either picking up the relevance of internal finance for investment or acting as as a proxy for investment opportunities. Finally, the results reported in column 5 show that the indicator for the probability of default, $p d$, displays the expected negative and statistically significant effect on investment ${ }^{10}$. This indicator being a composite measure based on several financial indicators, each of them weighted by its influence on the probability of default, its estimated coefficient in the investment equation reflects the impact of the financial situation on corporate investment, through its incidence on the probability of default.

Nevertheless, the relative importance of different financial variables in explaining the probability of default or the probability of failure might differ from their relative contribution to explaining real decisions of companies. Thus, in order to get a more precise picture of

\footnotetext{
${ }^{8}$ In our preferred estimates (those reported in the tables) we selected the instrument set in order that the Sargan test statistic reported was not significant at conventional levels, although these estimates proved very similar to those where the instrument set included instruments dated $t-2$ to $t-6$ in the first-differenced equation and $t-1$ in the levels equation.

${ }^{9} \mathrm{By}$ including this indicator we want to test whether debt is important once adjusted for liquidity. An indicator of liquidity (liquid assets divided by short term debt) turned out to be insignificant when included in both the investment and the employment equations.

${ }^{10}$ The estimate for this variable should be viewed with some caution since the reported standard errors do not take into account that it is an estimated regressor.
} 
the global impact of financial conditions on corporate behaviour, it is worth directly and simultaneously including several financial indicators in the estimated equations. Thus, it is possible to ascertain which specific financial features (indebtedness, profitability, financial burden...) are more relevant for each specific corporate decision.. Column 3 of Table 1 reports the estimates of the basic specification augmented with three financial variables at a time. As can be seen, those variables measuring the burden of servicing debt and profitability, $t d b$ and $(G R / A)$, although their point estimates are somewhat lower whenever the net debt term is included $^{11}$. As regards the net indebtedness indicator, a notable decline in the point estimate of its coefficient is observed when a profitability indicator is included and it is only marginally significant $^{12}$.

The estimation results for the employment equation are presented in Table 2. Column 1 reports the results of the basic specification without financial variables whereas columns 2 to 6 reports the results obtained when different financial variable are added to the specification. These results show the importance that financial factors have in explaining labour demand. The results in columns 2 show that debt has a negative (although non-significant) impact on labour demand. However, the indicators of total debt burden has a negative and highly significant impact on labour demand (column 3). Similarly, the results of the estimation when the gross revenue ratio is included are reported in columns 4, and show a positive and significant impact of the profitability indicator on employment demand. Also, as in the case of the investment equation, a negative and significant coefficient is found for the indicator of the probability of default, $p d$ (column 5). Finally, column 6 show that when three financial indicators are included in the regression (one for indebtedness, another for debt burden and the third one for profitability), the first is again non-significant whereas the indicators of debt burden and profitability remain significant and their point estimates (in absolute value) are only slightly reduced.

\footnotetext{
${ }^{11}$ Table 2 reports results for specifications including the gross revenue term $(G R / A)$. The pattern of results is qualitatively similar when the cash-flow term $(C F / A)$ is included instead of $G R / A$.

${ }^{12}$ The total debt ratio $(B / A)$ is never significant when additional financial variables are included. Moreover, this indicator is at the margin of significance $(p$-value $=0.15)$ when it is included as the only financial variable in the specification.
} 


\section{Non-linear effects}

The evidence presented in Section 2 shows that firms with a weaker financial situation -i.e. those firms belonging to the decile of the distribution characterised by the highest values of alternative proxies of financial pressure- have substantially lower investment and employment growth rates. However, in general, no significant differences in demand for factors of production are observed between the firms with least financial tightness and those with an average financial pressure. This evidence suggests that the relationship between the real activity of firms and their financial position is non-linear. Moreover, a more pronounced impact of this position on real activity once the financial pressure reaches a certain threshold seems reasonable. In this section, we provide a more formal analysis of this hypothesis. For this purpose, we estimate the investment and labour demand equations described in section 3 , but now allowing for a differential impact of financial conditions depending on the relative level of the corresponding financial indicator. We estimate the investment and employment models considering one financial indicator at a time. In each regression, we test whether the companies facing a high financial pressure -i.e. those firms in the upper decile (or quartile) of the distribution defined in terms of the corresponding financial indicator- are more sensitive to the financial conditions. More precisely, we estimate the following specifications:

$$
\begin{aligned}
\left(\frac{I}{K}\right)_{i t}= & \alpha_{i}+\beta_{1}\left(\frac{I}{K}\right)_{i t-1}+\beta_{2} \Delta y_{i t}+\beta_{3} \Delta y_{i t-1}+\beta_{4}(k-y)_{i t-2} \\
& +\gamma_{1} F_{i t} D_{0-75}^{F}+\gamma_{2} F_{i t} D_{75-90}^{F}+\gamma_{3} F_{i t} D_{90-100}^{F}+\theta_{t}+\varepsilon_{i t}
\end{aligned}
$$

and

$$
\begin{aligned}
n_{i t}= & \phi_{i}+\lambda_{1} n_{i t-1}+\lambda_{2} k_{i t}+\lambda_{3} w_{i t-1}+\lambda_{4} \Delta w_{i t}+\lambda_{5} \xi_{i t}+ \\
& +\eta_{1} F_{i t} D_{0-75}^{F}+\eta_{2} F_{i t} D_{75-90}^{F}+\eta_{3} F_{i t} D_{90-100}^{F}+\Psi_{t}+\mu_{i t}
\end{aligned}
$$

where $D_{0-75}^{F}, D_{75-90}^{F}$ and $D_{90-100}^{F}$ are dummy variables for observations below the 
75th percentile, between the 75th and 90th percentiles, and above the 90th percentile, respectively, of the distribution defined in terms of the financial variable $F$. When the corporate profitability measure $-(G R / A)$ - is used as financial indicator, we replace these dummies by $D_{0-10}^{F}, D_{10-25}^{F}$ and $D_{25-100}^{F}$, which are dummy variables for observations below the 10th percentile, between the 10 th and 25 th percentiles, and above the 25 th percentile. In these cases, the lower the percentile, the lower the profitability, and the higher, a priori, the degree of financial tightness.

\subsection{Results}

Table 3 reports the results obtained for investment when non-linearities are considered. In the specification allowing for a non-linear effect of net indebtness, we obtain evidence in favour of the existence of differences in the impact of this variable on investment, depending on its magnitude: net indebtedness is irrelevant for firms with low or moderate levels of net indebtedness (below the 75th percentile), whereas for those firms above this threshold it has a negative and significant impact both for the group between the 75 th and 90th percentiles and for the group in the upper decile.

When an indicator of debt burden is considered, results strongly support the existence of non-linearities: the indicator of total debt burden is significant for firms above the 90th percentile, whereas for fims between the 75 th and the 90 th percentile and for companies below the 75 th percentile, this indicator has not a significant impact on investment.

As for the profitability indicator, a positive and significant coefficient is obtained for those firms with higher profitability (those above the 25 th percentile). However, the coefficients for this variable are rather imprecisely estimated for the other two groupings. As expected, we obtain a higher coefficient for those companies in the lower tail of the distribution (a priori those facing a higher financial pressure). However, this coefficient is not significant ${ }^{13}$.

Ideally, we would like to allow for non-linearities in the effects of more than one financial

\footnotetext{
${ }^{13}$ When we use the cash-flow term, $(C F / A)$, instead of the gross revenue indicator, its coefficient for the companies in the lower tail of the distribution is significant and higher than the coefficients for the other two groupings.
} 
variable at a time. However, when simultaneously including different financial variables in a non-linear fashion, there is a sharp drop of significance in the interaction terms. For this reason, we opted for a mixed strategy by including one financial variable in a non linear-way and the rest of the financial variables linearly. Using this approach, the results of our preferred specification are reported in the last column of Table 3. In this specification, a linear effect is allowed for gross revenue over total assets and for net debt, while total debt burden enters in a non-linear way. We find, as expected, a positive coefficient for $(G R / A)$ and a negative one for net debt. ${ }^{14}$ Finally, a negative impact of total debt burden is only found for firms that are in the upper tail of the distribution.

Results for employment are shown in Table 4, and corroborate the existence of a nonlinear impact of financial variables on firms' real decisions. The indicators of net indebtedness and total debt burden are significant for firms in the upper decile of the distribution, for a 99 per cent confidence level, but for firms below the 90th percentile these indicators do not have a significant impact on employment. When profitability is considered, as was also the case for investment, the coefficient estimated for the lower decile is higher than that estimated for firms with higher profitability (above the 25th percentile). Moreover, the coefficient is only marginally significant for those companies with higher profitability. As in the case of investment, we also adopted a mixed strategy in the specification of the financial variables in the employment equation. The results of our preferred specification are reported in the last column of Table $4^{15}$. In this specification, a linear effect is allowed for gross revenue over total assets while total debt burden enters in a non-linear way. A positive and significant coefficient is found for the profitability term and a negative and significant one for total debt burden only for firms that are above the 90th percentile.

Overall, these results corroborate the descriptive evidence in Section 2 and point to the existence of threshold effects on the impact of financial variables on investment and employment. ${ }^{16}$ The specific threshold and the different sensitivities to the financial position seem to

\footnotetext{
${ }^{14}$ Profitability and net debt enter linearly in the specification, although in the table we present the coefficient for each of the three groups (which is equal for all of them) separately.

${ }^{15}$ The net debt term was dropped since it is not significant when jointly included with indicators of profitability and debt burden.

${ }^{16}$ Although the results clearly support this conclusion, it should be pointed out that the results reported in this section are more sensitive to the set of instruments used than those obtained for the linear specifications
} 
depend on the particular financial variable considered.

\section{Composite indicators of financial pressure}

In this section, we wish to construct synthetic indicators that summarise the non-linear influence that financing conditions have on investment and employment and to assess on the basis of them how the impact of financial conditions has evolved over time, with a special emphasis on the distribution across companies of this impact. For this purpose, we compute linear combinations of alternative sets of financial variables, where the relative weights are given by the estimated coefficients in the investment and the employment equations.

Thus, a financial conditions indicator for investment (FCII) and employment (FCIE) can be defined as follows:

$$
F C I I_{i t}=-\sum_{k} \hat{\gamma}^{k} X_{i t}^{k} \quad F C I E_{i t}=-\sum_{k} \hat{\eta}^{k} X_{i t}^{k}
$$

where $\hat{\gamma}^{k}\left(\hat{\eta}^{k}\right)$ is the estimated coefficient for financial variable $X^{k}$ in the investment (employment) equation.

These indicators measure the contributions of the financial variables in the investment and employment equations. As the sign of these contributions is changed, the higher the indicator the tighter the financial conditions faced by companies, i.e. the larger the negative impact of financial conditions on investment or employment. Since we have allowed for a nonlinear impact of financial variables, the differences in the indicator across firms will reflect not only differences in the financial position but also differences in the sensitivity of the real variables to this position. The lack of a proper measure of the effect of unobserved variables -including the unobserved individual time-invariant effect- makes it difficult to derive a precise measure of the importance of the financial conditions relative to the remaining determinants of investment and employment. However, these indicators represent a useful tool to compare (over time and across groups of companies) the importance of financial conditions in the demand for productive inputs.

presented in the previous section. 
Our starting point is to construct financial conditions indicators for investment and employment on the basis of the estimated coefficients of our preferred models in Section 4. In particular, our benchmark models are those in column 4 of Table 3 for fixed investment and column 4 of Table 4 for employment. Both models allow for a non-linear effect of the total debt burden $t d b_{i t-1}$, while restricting the impact of the gross revenue term $(G R / A)$ to be linear. In addition, the investment model also includes a linear net debt term $((B-m) / A)$.

In order to ascertain the relevance of financial variables for companies in different financial positions, it is useful to focus on different percentiles of the distribution of these indicators. More precisely, we present the evolution of the median value of these indicators as representative of the average financial pressure faced by the companies in our sample. We also show the evolution of the 90th percentile, to assess the time profile of the vulnerability of the companies facing a high financial pressure. Finally, we report the weighted average as an aggregate indicator of the position of the corporate sector as a whole. The weight for each firm in this indicator will be given by its contribution to total (aggregate) fixed assets, in the case of investment, or to total employment, in the case of employment. To compare the different percentiles and the weighted average of the financial indicators we normalise them by setting $F C I I_{1990}^{\text {median }}=100$ and $F C I E_{1990}^{\text {median }}=100$.

Figure 3 displays the different percentiles and the weighted average of the indicators for the impact of financing conditions on investment and employment. In the case of fixed investment (Panel A), the different percentiles and the weighted average display a similar countercyclical pattern. According to the median FCII, the second half of the 1980s was characterised by a relaxation of financial conditions which was mostly explained by the reduction in corporate debt in a period of high nominal interest rates and, to a lesser extent, by a certain recovery in corporate profitability. In the early 1990, this indicator shows a tightening of financial conditions as a result of an intense deterioration of corporate profitability. After reaching a peak in 1993, the median FCII declined continuously until 1998, owing to the reduction in the level of debt. In this period, there is also a modest improvement in corporate profitability. Finally, the median FCII displays a slight increase in the last three years of the sample owing to a slight reduction in corporate profits. 
The comparison of the median and the weighted average FCII shows that the weighted average presents higher values for the entire period, implying that the financial position for those firms that are more relevant for investment is weaker than that of the median. Furthermore, in some periods a different evolution pattern of behaviour is observed for the representative (median) firm and the weighted average. For instance, the important tightening in financial conditions observed in year 2001 for the weighted average is not so clearly seen in the median, that has shown a more stable behaviour in the last part of the sample.

Again, the comparison of the median FCII with the higher percentiles reveals that it is in the recessions, especially in the cyclical trough of 1993, when the impact of the financing conditions on investment increased relatively more for the most vulnerable companies than for companies with an average financial pressure. ${ }^{17}$ It is also worth noting that the observed increase in the median in the last years of the sample is not observed for the firms in the upper decile of the distribution.

In the case of employment (Panel B), our preferred financial indicator is a weighted average of the total debt burden and the gross-revenue term. The profile of the different percentiles of the FCIE is quite similar to that of the FCII. First, the different percentiles display a countercyclical pattern and, second, this pattern is more evident in the case of the highest percentile. Nevertheless, the weighted average indicator displays a larger cyclical variation than in the case of the FCII. Again, the median indicator is not a good proxy of the position of the sector as a whole, although in this case the difference between the median and the weighted average indicator diminished in the last part of the sample. In fact, the median exceeded the weighted average in the last part of the sample period (after 1998), something that was not seen in the FCII. The tightening in financial conditions observed in 2001 for the weighted average FCII is also seen in the FCIE.

Overall, this evidence shows the relevance of using firm-level data when analysing the changes in the financial position and suggests that financing conditions do not affect all

\footnotetext{
${ }^{17}$ As expected, the value of the 90th percentile of the indicator based on a non-linear specification is higher, over the whole sample period, than the value of the 90th percentile of an indicator constructed with the same variables but without considering non-linearities. And, interestingly, it is in the recession when this difference is larger. For the weighted average indicator, a linear especification also yields a degree of fragility persistently lower than that reported here, including non-linearities.
} 
companies equally. A tightening of financial conditions will have a significantly greater effect on the real decisions of those firms with lower financial soundness. This is particularly relevant in episodes where the financial pressure on a significant number of firms breaches the threshold at which it has a more intense influence on business activity. In these episodes, indicators based on aggregate data may not reliably reflect the system's financial soundness since they do not adequately reflect the deterioration of the financial position of the more vulnerable companies.

\section{Conclusions}

This paper has aimed to assess the impact of financial conditions on firms' real decisions, using a large-scale company-level panel dataset for the period 1985-2001. The analysis has focused on the behaviour of fixed investment and employment which are conceivably two of the most important aspects of adjustment by firms in response to changes in financial conditions. Within the general topic of the relationship between financial conditions and real activity, we have addressed three specific issues: first, the assessment of the relative importance of different financial variables in explaining the real decisions of firms; second, the analysis of the non-linearity in the relationship between financial proxies and real variables; and, finally, the construction of a synthetic indicator to capture the impact of financing conditions on investment (and, alternatively, on employment).

Our results strongly indicate that financial position is important to explain corporate decisions on fixed investment and employment. Several financial indicators turn out to be significant in the estimated equations. In particular, measures of the debt-service burden (both including and excluding the stock of short-term debt) remain significant when additional financial indicators are incorporated and their coefficients are quite robust. As regards profitability, its coefficient turns out to be significant in all specifications, although the point estimates depend on the additional financial variables included in the specification. Finally, the evidence for the indicator of indebtedness is less conclusive. In the investment equation the coefficient of the net debt term is significant. In the employment equation, the debt term is never significant in the linear specifications but it is significant for the upper decile of the 
distribution when considering non-linear specifications.

We have found evidence in favour of the hypothesis of a non-linear relationship between financial conditions and real activity. At a pure descriptive level, we have shown that the group of firms facing a higher degree of financial pressure, that we identify as those in the upper decile of the cross-sectional distribution of firms defined in terms of alternative financial indicators, have substantially lower investment and employment growth rates. The regression analysis has corroborated this result: the sensitivity of investment and employment to financial conditions is substantially larger for those firms in the upper quartile (or decile) of the distribution defined in terms of the corresponding financial indicator. Moreover, in some specifications, the financial variable is not significant for the companies facing a moderate (or low) degree of financial tightness. Overall, this evidence suggests that the real impact of financial conditions is non-linear and becomes relatively more intense when financial pressure exceeds a certain threshold. As a consequence, from the standpoint of identifying the risks to macroeconomic and financial stability, the use of firm-level data seems to be particularly relevant in episodes where the financial pressure on a significant number of firms reaches levels at which it has a more pronounced influence on real activity. In these episodes, indicators based on aggregate data may not reliably reflect the system's financial soundness since they do not adequately reflect the vulnerability of the most fragile companies. In addition, the analysis of our composite indicators constructed at the firm-level reveals that neither the level nor the changes in the financial pressure experienced by the representative (median) firm is an accurate measure of the financial pressure faced by the corporate sector. In fact, in 2001 -the last year of our sample period-, the observed increase in our median indicators is much lower than that observed for the weighted average. 


\section{Data Appendix}

The data employed are derived from an annual survey of non-financial firms conducted by the Central Balance Sheet Data Office of the Banco de España (see Banco de España, 2002). This is a large scale survey used extensively by the Banco de España to inform its assessment of the Spanish corporate sector. In terms of gross value added the survey respondents jointly represent around 35 per cent of the total gross value added of the non-financial corporate sector in Spain, and the pattern of evolution of the aggregate values for the main variables used here (employment, investment) is quite similar to that observed in the whole economy. This paper employs data for the period 1985 to 2001 for which the coverage of the survey has been relatively stable. Data are only used when there are at least 5 consecutive timeseries observations per company. This produces an unbalanced sample of 7,547 non-financial companies and 70,625 observations with between 5 and 17 annual observations per company.

Table A.1: Panel structure. Number of time-series observations per company

\begin{tabular}{l|ccccccc}
\hline \hline No of observations & 5 & 6 & 7 & 8 & 9 & 10 & 11 \\
Companies & 1,268 & 1,109 & 913 & 658 & 581 & 379 & 352 \\
\hline No of observations & 12 & 13 & 14 & 15 & 16 & 17 & Total \\
Companies & 411 & 365 & 415 & 400 & 234 & 462 & 7,547 \\
\hline \hline
\end{tabular}

Table A.2: Sample medians

\begin{tabular}{ll|ccccc}
\hline \hline & & $1985-1988$ & $1989-1992$ & $1993-1996$ & $1997-2001$ & $1985-2001$ \\
\hline$I / K$ & investment rate & 0.118 & 0.103 & 0.076 & 0.111 & 0.100 \\
$N$ & employment & 65 & 47 & 35 & 37 & 43 \\
$Y$ & real sales (1995 prices) & 7580.6 & 5525.9 & 4213.92 & 4357.3 & 5088.8 \\
$\Delta y$ & sales growth & 0.038 & -0.007 & 0.013 & 0.041 & 0.021 \\
$\Delta w$ & wage growth & 0.012 & 0.022 & 0.004 & 0.005 & 0.010 \\
$B / A$ & debt & 0.301 & 0.247 & 0.269 & 0.249 & 0.263 \\
$(B-m) / A$ & net indebtedness & 0.207 & 0.164 & 0.173 & 0.140 & 0.168 \\
$i d b$ & interest debt burden & 0.188 & 0.216 & 0.214 & 0.100 & 0.167 \\
$t d b$ & total debt burden & 1.052 & 1.037 & 1.013 & 0.714 & 0.944 \\
$G R / A$ & gross revenue & 0.216 & 0.188 & 0.162 & 0.168 & 0.179 \\
$C F / A$ & cash-flow & 0.130 & 0.105 & 0.095 & 0.115 & 0.110 \\
$p d$ & probabilty of default & 0.007 & 0.009 & 0.012 & 0.007 & 0.009 \\
\hline observations & & 12,444 & 18,294 & 19,448 & 20,439 & 70,625 \\
\hline \hline
\end{tabular}

Investment $(I)$

Purchase of new fixed assets.

Capital stock $(K)$

Fixed assets at replacement cost (calculated by the Central Balance Sheet Data Office (CBSO) of the Banco de España). When introduced in real terms, $K$ is deflated by the Gross Fixed Capital Formation deflator.

Total assets $(A)$ 
This is given by the sum of fixed assets at replacement cost $K$ and working capital less provisions.

Employment $(N)$

The number of employees during the year. The data also distinguish between the number on permanent and temporary contracts.

Real Sales $(S)$

Total company sales, deflated by the GDP deflator.

Wages $(W)$

The average company wage is given by direct employment costs (not including social security contributions) divided by the employment head count and deflated by the GDP deflator.

Gross revenue over total assets $(G R / A)$

Gross operating profit plus financial revenue divided by total assets.

Debt $(B / A)$

Total outstanding debt divided by total assets.

Net Debt $((B-m) / A)$

Total outstanding debt less cash and its equivalents divided by total assets.

Interest debt burden (idb)

Interest payments divided by gross revenue.

Total debt burden $(t d b)$

Interest payments plus short-term debt over gross revenue.

Cash flow $(C F / A)$

Post-tax profit plus depreciation of fixed assets divided by total assets.

Probability of default $(p d)$

Based on Benito et al (2004), it is obtained from the estimation of a probit model which has as explanatory variables real sales, debt, interest debt burden, short-term debt without cost over total debt, profitability, liquidity, a dummy indicating if the firm pays dividends and the growth rate of gross domestic product.

For interest debt burden and total debt burden, where companies have a negative or zero value for the denominator and a positive value for the numerator the ratio is set equal to the value of the 99th percentile that year; where the numerator is zero, the ratio is set equal to zero, for any value of the denominator. Additionally, for all the variables used as regressors (except those that enter in levels), when the value is higher than the 99th percentile, it is changed for the value of this percentile. 


\section{References}

Arellano, M., Bond, S., 1998. 'Dynamic Panel Data Estimation Using DPD98 for GAUSS: A Guide for Users', mimeo, Institute for Fiscal Studies.

Arellano, M., Bond, S., 1991. 'Some Tests of Specification for Panel Data: Monte Carlo Evidence and an Application to Employment Equations', Review of Economic Studies, $58,277-97$.

Arellano, M., Bover, O., 1995. 'Another Look at the Instrumental-Variable Estimation of Error-Components Models', Journal of Econometrics, 69, 29-52.

Banco De Espa ̃a, 2002. Results of Non-financial Corporations. Annual Report 2001, Central Balance Sheet Data Office, Banco de España.

Benito, A., Delgado, J., Martínez-Pagés, J., 2004. 'A synthetic indicator of Spanish non-financial firms' fragility', Banco de España Working Paper No. 0411.

Benito, A., Hernando, I., 2002. 'Extricate: Financial Pressure and Firm Behaviour in Spain', Banco de España Working Paper No. 0227.

Benito A., Vlieghe G. W., 2000. 'Stylised Facts of UK Corporate Health: Evidence From Micro-data', Bank of England Financial Stability Review, June, 83-93.

Benito, A., Young, G., 2002. 'Financial Pressure and Balance Sheet Adjustment by UK firms', Banco de España Working Paper No. 0209.

Bentolila, S., Saint-Paul, G., 1992. 'The Macroeconomic Impact of Flexible Labor Contracts with an Application to Spain', European Economic Review, 36, 1013-1053.

Blundell, R.W., Bond, S., 1998. 'Initial Conditions and Moment Restrictions in Dynamic Panel Data Models', Journal of Econometrics, 87, 115-143.

Bond, S., Elston, J., Mairesse, J., Mulkay, B., 2003. 'Financial Factors and Investment in Belgium, France, Germany and the United Kingdom: a Comparison using Company Panel Data', The Review of Economics and Statistics, 85(1), 153-165.

Bond, S., Harhoff, D., Van Reenen, J., 1999. 'Investment, R\&D and Financial Constraints in Britain and Germany', Institute for Fiscal Studies Working Paper 99/5.

Fazzari, S., Hubbard, R.G., Petersen, B., 1988. 'Financing Constraints and Corporate Investment', Brookings Papers on Economic Activity, No. 1, 141-195.

Hubbard, R.G., 1998. 'Capital Market Imperfections and Investment', Journal of Economic Literature, 36, 193-225.

Modigliani, F., Miller, M., 1958. 'The Cost of Capital, Corporation Finance, and the Theory of Investment', American Economic Review, 48, 261-297. 
Nickell, S., Nicolitsas, D., 1999. 'How Does Financial Pressure Affect Firms?', European Economic Review, 43, 1435-1456.

Nickell, S., Wadhwani, S., 1991. 'Employment Determination in British Industry: Investigations Using Micro-data', Review of Economic Studies, 58, 955-969.

OGawa, K., 2003. 'Financial distress and employment: The Japanese case in the 90s', NBER Working Paper No. 9646.

Vermeulen, P. (2002), 'Business Fixed Investment: Evidence of a Financial Accelerator in Europe', Oxford Bulletin of Economics and Statistics, 64, 213-231. 


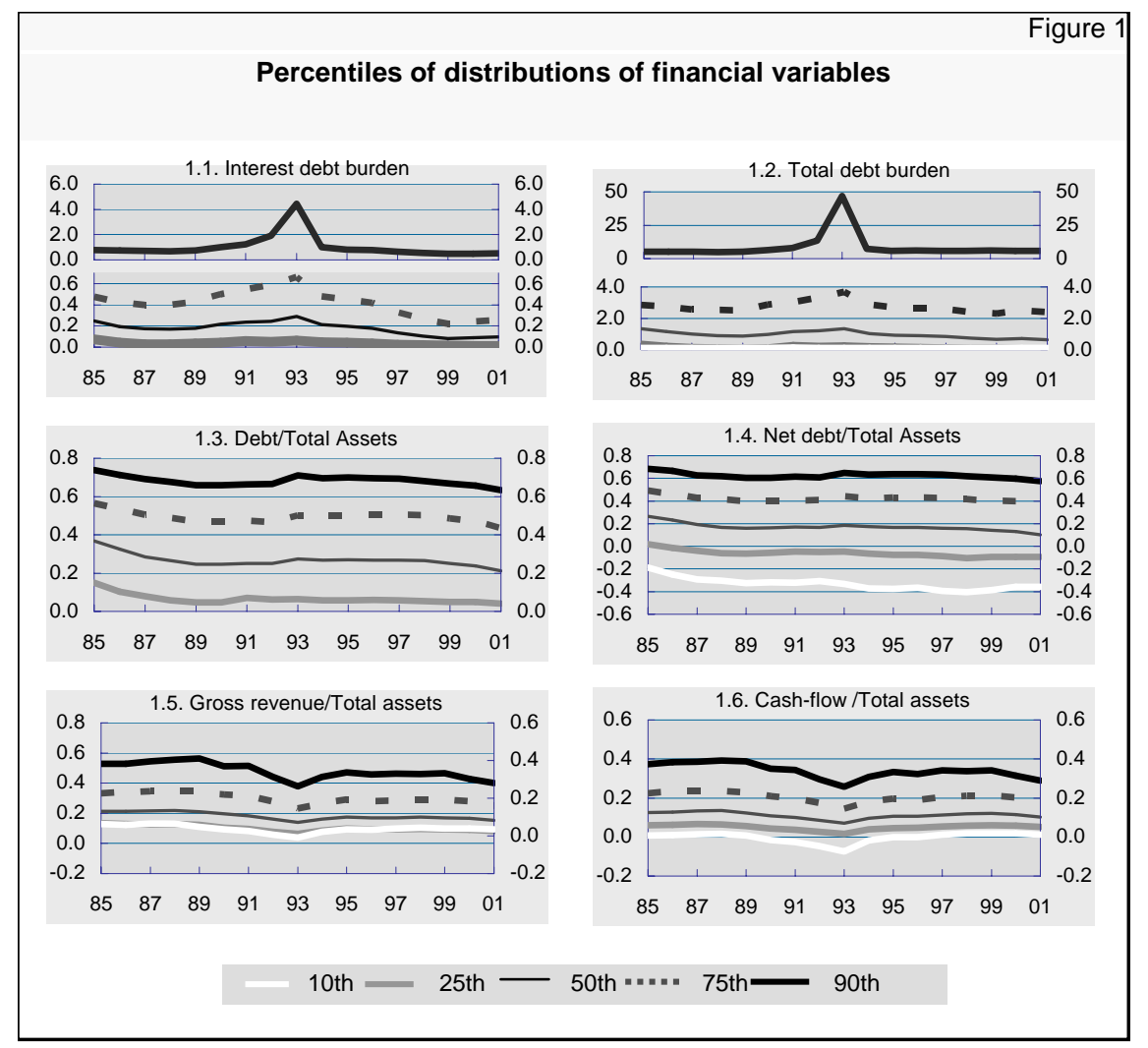


Financial position and level of activity
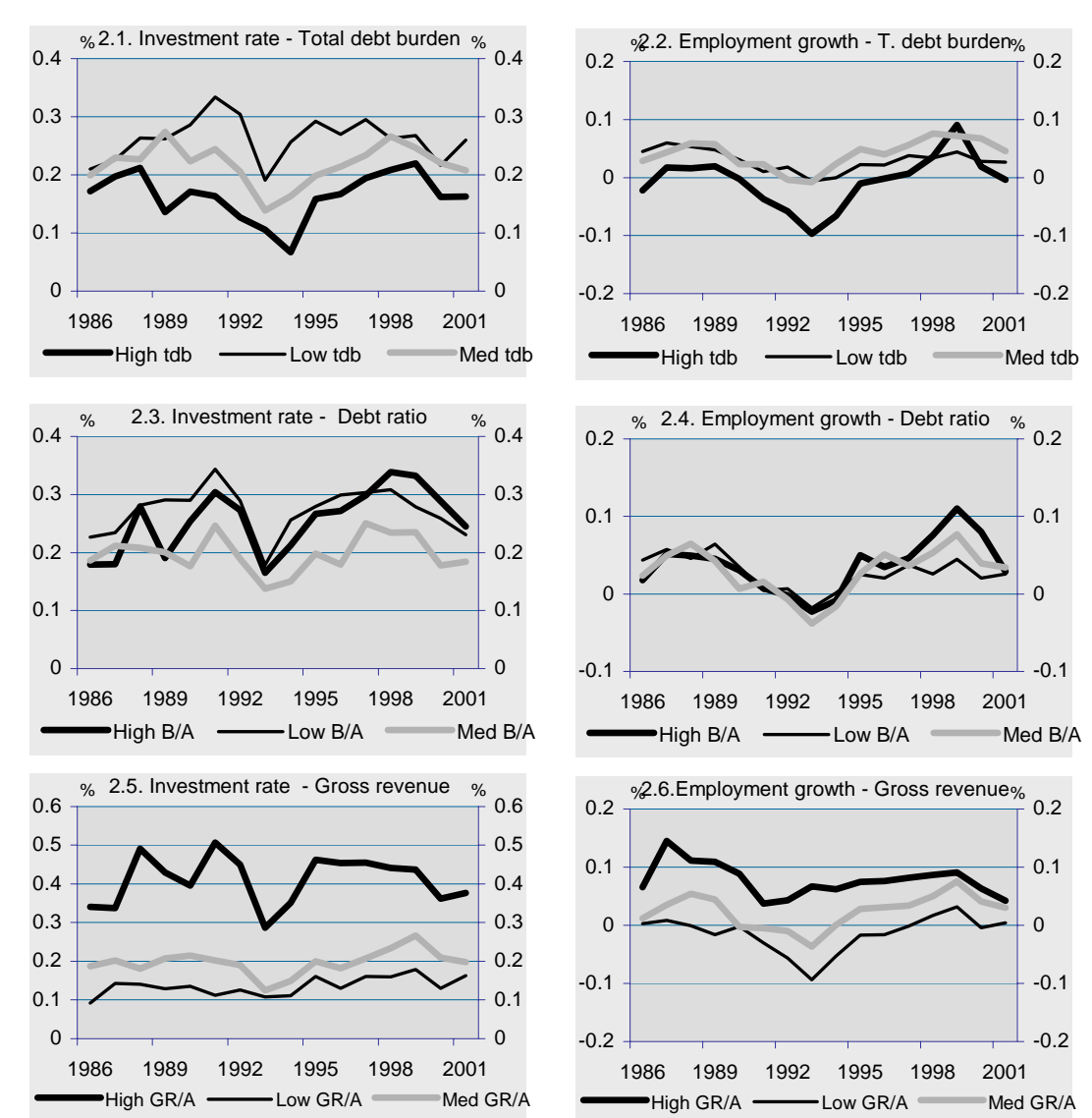
Figure 3

COMPOSITE INDICATORS OF THE IMPACT OF FINANCIAL CONDITIONS

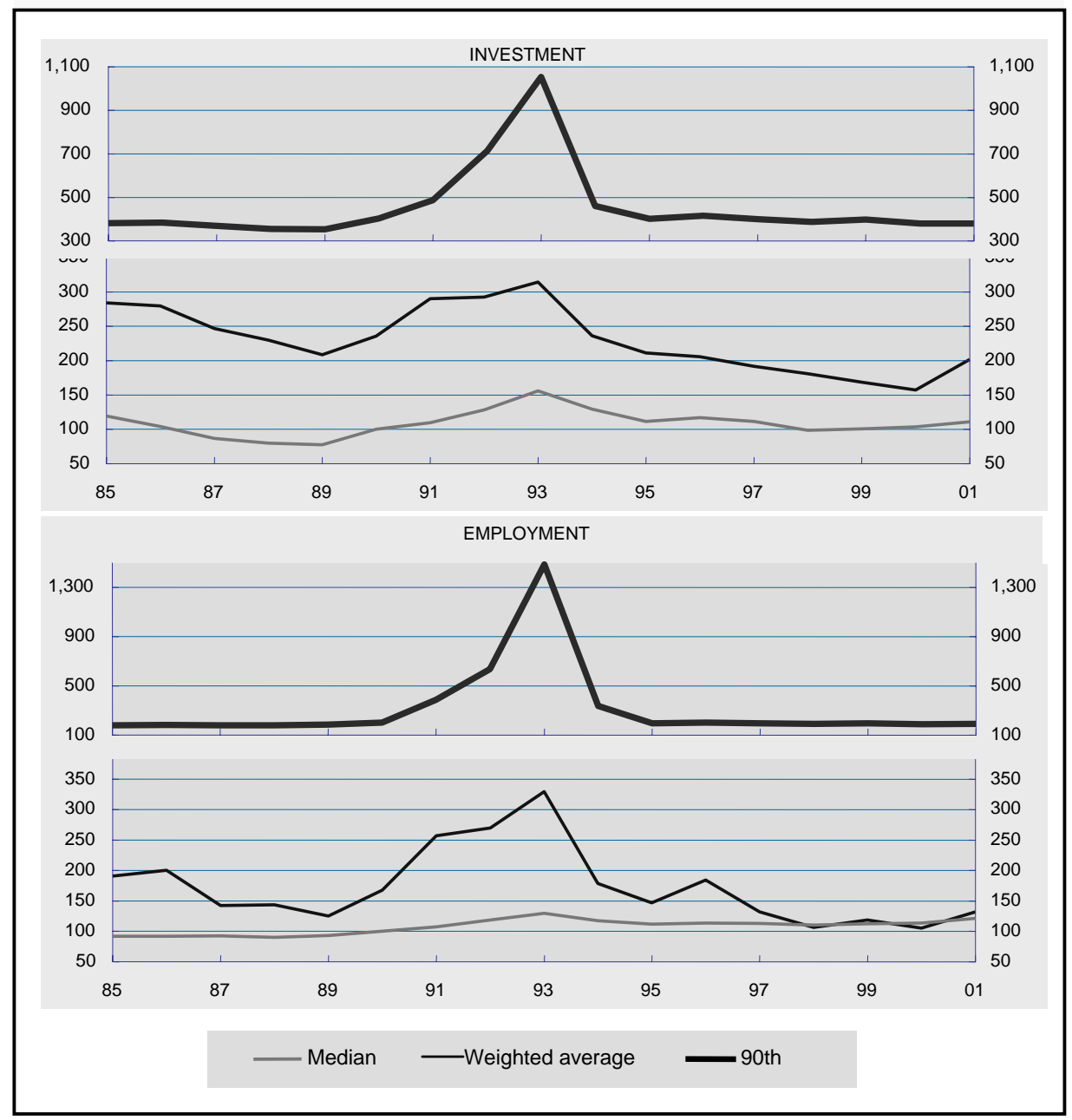


Table 1: Fixed investment

\begin{tabular}{l|cccccc}
\hline \hline \multicolumn{1}{c|}{$(I / K)_{i t}$} & {$[1]$} & {$[2]$} & {$[3]$} & {$[4]$} & {$[5]$} & {$[6]$} \\
\hline$(I / K)_{i t-1}$ & $-0.057(0.099)$ & $-0.084(0.057)$ & $-0.055(0.085)$ & $-0.113(0.087)$ & $-0.037(0.079)$ & $-0.117(0.057)$ \\
$\Delta y_{i t}$ & $0.358(0.124)$ & $0.347(0.109)$ & $0.294(0.098)$ & $0.386(0.113)$ & $0.271(0.099)$ & $0.292(0.084)$ \\
$\Delta y_{i t-1}$ & $0.334(0.112$ & $0.379(0.088)$ & $0.260(0.086)$ & $0.290(0.104)$ & $0.205(0.059)$ & $0.364(0.071)$ \\
$(k-y)_{i t-2}$ & $-0.175(0.022)$ & $-0.171(0.017)$ & $-0.162(0.020)$ & $-0.158(0.019)$ & $-0.158(0.018)$ & $-0.160(0.017)$ \\
$((B-m) / A)_{i t-1}$ & & $-0.091(0.027)$ & & & $-0.044(0.031)$ \\
$t d b_{i t-1}$ & & & $-0.004(0.001)$ & & $-0.002(0.001)$ \\
$(G R / A)_{i t-1}$ & & & & $0.331(0.126)$ & & $0.153(0.065)$ \\
$(p d)_{i t-1}$ & & & & $-0.938(0.352)$ & \\
\hline & & & & & 0.000 & 0.000 \\
\hline$M_{1}$ & 0.000 & 0.000 & 0.000 & 0.000 & 0.539 & 0.465 \\
$M_{2}$ & 0.785 & 0.903 & 0.739 & 0.747 & 0.229 & 0.257 \\
Sargan & 0.188 & 0.402 & 0.374 & 0.156 & 0.999 & 0.319 \\
Difference-Sargan & 0.985 & 0.893 & 0.999 & 0.985 & 7,547 & 7,547 \\
companies & 7,547 & 7,547 & 7,547 & 7,547 & 55,531 & 55,531 \\
observations & 55,531 & 55,531 & 55,531 & 55,531 & & \\
\hline \hline
\end{tabular}
(Blundell and Bond, 1998; Arellano and Bond, 1998). Sargan is a Sargan Test of over-identifying restrictions (p-value reported), with a chi-square distribution under the null of instrument validity. Difference-Sargan is a Sargan Test of the additional moment conditions associated with the levels equations (p-value reported), distributed as a chi-square under the null of instrument validity. $M_{j}$ is a test of $j$ th-order serial correlation in the first-differenced residuals (p-values reported). These are both distributed as standard normals under the null hypotheses. Asymptotic robust standard errors reported in parentheses. Instruments: in first-differences equation, following lagged values of the regressors: $\Delta y, G R / A$ $(\mathrm{t}-4, \mathrm{t}-5),(k-y)(\mathrm{t}-5, \mathrm{t}-6)(B-m) / A(\mathrm{t}-2$ to $\mathrm{t}-5), t d b, p d$ (t-3 to $\mathrm{t}-5)$. In levels equations, first differences of the regressors dated as follows: $I / K, \Delta y,(B-m) / A, t d b(\mathrm{t}-2), p d(\mathrm{t}-1),(k-y), G R / A(\mathrm{t}-3)$. 
Table 2: Employment

\begin{tabular}{|c|c|c|c|c|c|c|}
\hline & {$[1]$} & {$[2]$} & {$[3]$} & {$[4]$} & {$[5]$} & {$[6]$} \\
\hline$n_{i t-1}$ & $0.915(0.020)$ & $0.910(0.017)$ & $0.941(0.017)$ & $0.927(0.019)$ & $0.925(0.017)$ & $0.951(0.015)$ \\
\hline$k_{i t}$ & $0.039(0.008)$ & $0.042(0.007)$ & $0.030(0.007)$ & $0.034(0.007)$ & $0.039(0.008)$ & $0.027(0.007)$ \\
\hline$\Delta w_{i t}$ & $-0.535(0.118)$ & $-0.522(0.104)$ & $-0.507(0.101)$ & $-0.501(0.099)$ & $-0.436(0.110)$ & $-0.522(0.073)$ \\
\hline$w_{i t-1}$ & $-0.017(0.053)$ & $-0.002(0.048)$ & $-0.037(0.043)$ & $-0.012(0.046)$ & $0.007(0.047)$ & $-0.034(0.035)$ \\
\hline$\Delta y_{i t}$ & $0.303(0.047)$ & $0.301(0.044)$ & $0.299(0.044)$ & $0.306(0.043)$ & $0.312(0.043)$ & $0.274(0.033)$ \\
\hline$((B-m) / A)_{i t-1}$ & & $-0.010(0.013)$ & & & & $0.010(0.016)$ \\
\hline$t d b_{i t-1}$ & & & $-0.003(0.001)$ & & & $-0.003(0.001)$ \\
\hline$(G R / A)_{i t-1}$ & & & & $0.113(0.041)$ & & $0.112(0.020)$ \\
\hline$(p d)_{i t-1}$ & & & & \multicolumn{3}{|c|}{$0.856(0.373)$} \\
\hline$M_{1}$ & 0.000 & 0.000 & 0.000 & 0.000 & 0.000 & 0.000 \\
\hline$M_{2}$ & 0.082 & 0.075 & 0.068 & 0.088 & 0.105 & 0.035 \\
\hline Sargan & 0.443 & 0.444 & 0.647 & 0.362 & 0.273 & 0.591 \\
\hline Difference-Sargan & 0.075 & 0.406 & 0.283 & 0.083 & 0.044 & 0.187 \\
\hline companies & 7,547 & 7,547 & 7,547 & 7,547 & 7,547 & 7,547 \\
\hline observations & 55,531 & 55,531 & 55,531 & 55,531 & 55,531 & 55,531 \\
\hline
\end{tabular}

Notes: All equations include time dummies (year effects). Estimation by GMM-SYSTEM estimator using the robust one-step method

(Blundell and Bond, 1998; Arellano and Bond, 1998). Sargan is a Sargan Test of over-identifying restrictions (p-value reported), with a chi-square distribution under the null of instrument validity. Difference-Sargan is a Sargan Test of the additional moment conditions associated with the levels equations (p-value reported), distributed as a chi-square under the null of instrument validity. $M_{j}$ is a test of $j$ th-order serial correlation in the firstdifferenced residuals ( $\mathrm{p}$-values reported). These are both distributed as standard normals under the null hypotheses. Asymptotic robust standard errors reported in parentheses. Instruments: in first-differences equation, following lagged values of the regressors: $n,(B-m) / A(\mathrm{t}-5), k, \Delta y, \Delta w$ $(\mathrm{t}-5, \mathrm{t}-6), w, G R / A(\mathrm{t}-4, \mathrm{t}-5), t d b, p d(\mathrm{t}-4$ to $\mathrm{t}-6)$. In levels equations, first differences of the regressors dated as follows: $n, \Delta w,(B-m) / A(\mathrm{t}-2)$, $t d b, p d(\mathrm{t}-3), G R / A(\mathrm{t}-4)$. 
Table 3: Investment. Non-linear effects.

\begin{tabular}{|c|c|c|c|c|}
\hline & [1] & {$[2]$} & {$[3]$} & {$[4]$} \\
\hline$(I / K)_{i t-1}$ & $-0.076(0.069)$ & $-0.098(0.074)$ & $-0.114(0.076)$ & $-0.141(0.050)$ \\
\hline$\Delta y_{i t}$ & $0.346(0.093)$ & $0.261(0.093)$ & $0.344(0.090)$ & $0.284(0.077)$ \\
\hline$\Delta y_{i t-1}$ & $0.354(0.091)$ & $0.335(0.087)$ & $0.356(0.088)$ & $0.361(0.067)$ \\
\hline$(k-y)_{i t-2}$ & $-0.166(0.018)$ & $-0.170(0.019)$ & $-0.166(0.019)$ & $-0.162(0.016)$ \\
\hline$((B-m) / A)_{i t-1}(<p 75)$ & $-0.061(0.047)$ & & & $-0.052(0.030)^{*}$ \\
\hline$((B-m) / A)_{i t-1}(>p 75 ;<p 90)$ & $-0.147(0.062)$ & & & $-0.052(0.030)^{*}$ \\
\hline$((B-m) / A)_{i t-1}(>p 90)$ & $-0.127(0.048)$ & & & $-0.052(0.030)^{*}$ \\
\hline$(t d b)_{i t-1}(<p 75)$ & & $-0.007(0.008)$ & & $-0.004(0.007)$ \\
\hline$(t d b)_{i t-1}(>p 75 ;<p 90)$ & & $-0.005(0.010)$ & & $0.011(0.010)$ \\
\hline$(t d b)_{i t-1}(>p 90)$ & & $-0.004(0.001)$ & & $-0.002(0.001)$ \\
\hline$(G R / A)_{i t-1}(>p 25)$ & & & $0.202(0.101)$ & $0.165(0.063)^{*}$ \\
\hline$(G R / A)_{i t-1}(>p 10 ;<p 25)$ & & & $0.662(1.103)$ & $0.165(0.063)^{*}$ \\
\hline$(G R / A)_{i t-1}(<p 10)$ & & & $0.658(0.727)$ & $0.165(0.063)^{*}$ \\
\hline$M_{1}$ & 0.000 & 0.000 & 0.000 & 0.000 \\
\hline$M_{2}$ & 0.988 & 0.812 & 0.643 & 0.201 \\
\hline Sargan & 0.254 & 0.259 & 0.082 & 0.187 \\
\hline Difference-Sargan & 0.882 & 0.803 & 0.849 & 0.684 \\
\hline companies & 7,547 & 7,547 & 7,547 & 7,547 \\
\hline observations & 55,531 & 55,531 & 55,531 & 55,531 \\
\hline
\end{tabular}

Notes: See notes to Table 1. (*) Coefficients restricted to be equal. 
Table 4: Employment. Non-linear effects.

\begin{tabular}{|c|c|c|c|c|}
\hline & {$[1]$} & {$[2]$} & {$[3]$} & {$[4]$} \\
\hline$n_{i t-1}$ & $0.905(0.015)$ & $0.931(0.014)$ & $0.926(0.016)$ & $0.958(0.013)$ \\
\hline$k_{i t}$ & $0.041(0.007)$ & $0.034(0.007)$ & $0.032(0.007)$ & $0.019(0.006)$ \\
\hline$\Delta w_{i t}$ & $-0.492(0.092)$ & $-0.550(0.087)$ & $-0.637(0.080)$ & $-0.554(0.075)$ \\
\hline$w_{i t-1}$ & $0.043(0.041)$ & $-0.003(0.035)$ & $0.012(0.040)$ & $-0.050(0.032)$ \\
\hline$\Delta y_{i t}$ & $0.293(0.042)$ & $0.286(0.038)$ & $0.280(0.038)$ & $0.280(0.035)$ \\
\hline$((B-m) / A)_{i t-1}(<p 75)$ & $-0.001(0.015)$ & & & \\
\hline$((B-m) / A)_{i t-1}(>p 75 ;<p 90)$ & $0.001(0.025)$ & & & \\
\hline$((B-m) / A)_{i t-1}(<p 90)$ & $-0.052(0.023)$ & & & \\
\hline$(t d b)_{i t-1}(<p 75)$ & & $0.006(0.004)$ & & $0.005(0.005)$ \\
\hline$(t d b)_{i t-1}(>p 75 ;<p 90)$ & & $-0.001(0.004)$ & & $0.006(0.005)$ \\
\hline$(t d b)_{i t-1}(>p 90)$ & & $-0.004(0.001)$ & & $-0.003(0.001)$ \\
\hline$(G R / A)_{i t-1}(>p 25)$ & & & $0.090(0.012)$ & $0.085(0.019)^{*}$ \\
\hline$(G R / A)_{i t-1}(>p 10 ;<p 25)$ & & & $0.116(0.060)$ & $0.085(0.019)^{*}$ \\
\hline$(G R / A)_{i t-1}(<p 10)$ & & & $0.304(0.090)$ & $0.085(0.019)^{*}$ \\
\hline$M_{1}$ & 0.000 & 0.000 & 0.000 & 0.000 \\
\hline$M_{2}$ & 0.052 & 0.039 & 0.045 & 0.048 \\
\hline Sargan & 0.334 & 0.155 & 0.567 & 0.440 \\
\hline Difference-Sargan & 0.332 & 0.149 & 0.086 & 0.164 \\
\hline companies & 7,547 & 7,547 & 7,547 & 7,547 \\
\hline observations & 55,531 & 55,531 & 55,531 & 55,531 \\
\hline
\end{tabular}

